\title{
Google class in ELT: A study of Student's Responses in English for Nutrition
}

\author{
Tiyas Saputri, tiyass@unusa.ac.id, Universitas Nahdlatul Ulama Surabaya, Surabaya, \\ Indonesia \\ Mujad Didien Afandi, dinosetro@unusa.ac.id, Universitas Nahdlatul Ulama Surabaya, \\ Surabaya, Indonesia \\ Badril Alamsyah, badrilalamsyah031.ig18@student.unusa.ac.id, Universitas Nahdlatul \\ Ulama Surabaya, Surabaya, Indonesia
}

\begin{abstract}
Google Classroom (GC) is one of the best platforms produced by Google that has some purposes for education, especially in the teaching and learning process. In the S1 Nutrition department, the application of Google Classroom is still rarely used and still few lecturers of the Nahdlatul Ulama University of Surabaya use this application maximally for teaching any courses, including in teaching English. This research aims to find out the students' responses to using GC in the English Class of the nutrition profession. This paper also presents GC features and the benefits of using it. The participants have had some experience in using it. The participants are 37 students from three classes chosen through random sampling. The data was collected through a questionnaire survey from the students' responses. The data then was analyzed qualitatively. The results presented that from statements 1-10, only statement 1 (GC can accommodate e-learning) and statement 9 (GC is easy to use) which have reached 64,9\% (Agree). The lowest percentage was $45,9 \%$ (GC is as a character-building). They agreed that GC has many benefits and the priorities of benefit to accommodate elearning and easy to use. However, it still needs to be explored further of the direct impact on the students for building their character.
\end{abstract}

Keywords: Google Classroom; Students' responses; Teaching and Learning

\section{A. INTRODUCTION}

Google Classroom (GC) is produced by Google that has some purposes for education, especially in the teaching and learning process, and is considered as one of the best platforms. It was launched by Google Apps for Education (GAFE) in 2014 (Megawati \& Astutik, 2019). It has been connected to other features such as Google Drive and others. To use this application, the users are required to have a g-mail account. It is free of charge and no need to take a long time to comprehend how it works. It is for anyone with Google Apps for Education, a free suite of productivity tools which includes Gmail, Drive, and Docs. It provides a set of powerful options that create it a perfect tool to use with students. It helps academics save time, make classes organized, and improve communication with students.

GC is supposed to assist academics to manage the creation and assortment of student assignments in a very paperless setting, essentially investing the framework of Google Docs, Drive, and different Apps. It permits academics to take time with their students and less time on the work, and it is currently even higher. Google's latest announcement brings new practicality to Google Classroom. The new function is the ability to add more than one teacher and prepare for classes in advance as well. It is not difficult to use GC. Once a new 
course is created, the teacher can see three taps. These are labeled as about, students, and stream. On the same page, on the bottom of the right side, he or she will see a sign. If the teacher clicks on it, four different tabs can open named reuse post, make a question, assignment, and announcement. He or she can keep all files in Google Drive. He or she can grade, attach YouTube, or any links for educational purposes. From GC, a teacher will send mail to all students at a time. Janzen, (2014) points out the advantages of using Google Classroom: 1. Easy to use, 2. Saves time, 3. Cloud-based, 4. Flexible Free, 5. Mobile-friendly: Google Classroom is intended to be responsive.

Keeler, (2014) mentioned another benefit of using GC is how it ensures streamline counseling only by posting an announcement. Also, Ann D. Thompson, (2015) stated that GC facilitates collaborative learning. Therefore, it can be used for collaboration between the teacher and the students throughout the teaching and learning process.

Many research papers related to e-learning, online, or blended learning although the number of research papers focusing on GC as a means of learning is still few. One of the new studies by Jakkaew, (2017) to analyze the factors that influence the application of GC in individual courses, using a single theory of acceptance and use of technology model. The survey was obtained from the students who enrolled in these courses with 24 five-point Likert-scale questions. The findings support the fact that GC can improve the cognitive abilities of the students' self-directed learning (SDL). The study uses 'The Google Form questionnaires' as an instrument to assess the users' satisfaction and self-evaluation level.

As a tool for improving teaching and learning processes around the world, Google Classroom (GC) is open. A study conducted in Bangladesh aims to examine the relevance of this e-learning method for both students and faculty members. This focuses on certain variables that depend on the poor participation of GC students. The most significant results illustrate the fact that students prefer GC participation where teachers have passive roles rather than being active in a passive role. When the GC is compared to Facebook, however, the GC suffers from such constraints (Iftakhar, 2016). A questionnaire that has been built to serve the same function collects the data. "The analysis of the results of the questionnaire shows that this study can be efficient in understanding and evaluating the perception of teachers and learners to ensure quality teaching and learning through Google Classroom" (Iftakhar, 2016).

As presented in a study by Dicicco, (2016), GC can play an important role in improving learning skills with learning disabilities, indicating that the Google Classroom can be effective in social studies and that it can enhance the learning skills of students in the field of vocabulary growth and unit testing. The study shows that while students can increase the amount of vocabulary, they still suffer from some limitations to the extent of content awareness.

Although the students of the nutrition profession have applied GC totally in the English learning process they have already had some experiences to share during applying it. Therefore, in this research, the researcher would like to find out the students' responses to using it in the English Class of the nutrition profession. Besides, it is important to explore GC features and the benefits of using it during the teaching and learning process. The purpose of the study is to find out the students' responses to using GC in the English Class of the nutrition profession. To ensure quality teaching and learning across this medium, the urgency of this research is to use it more efficiently in the teaching and learning process. 
In teaching practice, instruction variation needs to be developed to encourage students' motivation in learning. Implementing GC is one way conducted by educators recently. Some previous studies have shown the teachers' perspective on the practice (Azhar \& Iqbal, 2018). In line with this, Iftakhar, (2016) has observed factors behind the use of GC, the way in using $\mathrm{GC}$, the problems found during the action, and students' view after experiencing a virtual classroom with the help of GC. Furthermore, Al-maroof \& Al-emran, (2018) investigated the adoption of GC by students studied and the findings showed that both perceived ease of use (PEOU) and perceived utility (PU) have a major effect on the behavioral intention of undergraduates. In the area of language learning, the use of GC can be investigated further. Not much students' and teachers' view is found out on Google Classroom for English language instruction. One of them has investigated the use of the application in Listening skills (Rabbi et al., 2017). The study found Google Classroom is a tool that can give positive impacts to enhance the students 'listening skill level. The possibility to reach language learning has a lot of spaces to be explored here. Furthermore, Megawati \& Astutik, (2019) stated that Google Classroom can be one of the teachers' assistance for their classes, including in the assessment. Considering the high potential obtained from digital-based instruction in the form of Google Classroom, particularly, for English teaching and learning process which is not broadly touched yet.

It is really simple to build and to use Google Classroom. All available characteristics are combined here. The teacher can see three taps until a new course space is developed. These are labeled as streams, students, and about. On the same side, he or she will see a plus sign on the bottom of the right. Four separate tabs will open called reuse article, create a query, create an assignment, and create an announcement if the teacher clicks on it. All files can be saved on Google Drive by an instructor. For instructional purposes, he or she can score, connect your tube, or any connection. A teacher can send mail to all students at a time, from Google Classroom.

Janzen, (2014) the following advantages of using Google Classroom are highlighted: quick to use, time-saving, cloud-based, versatile, free, and mobile-friendly. Dealing with GC is very simple to use, Janzen, (2014) said that the nature of GC intentionally simplifies the instructional interface and options used to deliver and monitor tasks; contact with the entire course or individuals is also simplified through alerts, email, and push notifications. Also, GC is planned to save time. The process of handling document delivery, grading, formative assessment, and reviews are simplified and streamlined by incorporating and automating the use of other Google applications, including papers, slides, and spreadsheets. Chehayeb, (2015) reported that Google is releasing some features such as Google Sheets export grades, grade point scale easier to update, grade entry keyboard navigation, grading page sort by name, etc to save time for teachers.

As Google apps reflect a large portion of cloud-based corporate collaboration platforms used by the skilled workforce, GC provides more professional and authentic technology to be used in learning environments (Iftakhar, 2016). Also, in both face-to-face learning environments and a completely online environment, this app is readily accessible and available for instructors and learners. This helps educators to more effectively explore and impact flipped instructional approaches, as well as simplify and coordinate the delivery and selection of tasks and communications in different educational environments (Iftakhar, 2016). 
Without admission to an educational institution, GC itself is not generally open to learners. But by simply signing up for a Google account, anyone can access any of the other applications, such as Drive, Docs, Spreadsheets, Slides, etc. It is designed to be receptive. On any mobile device, it is simple to use. Mobile access to enticing and easy-to-interact learning materials is important in today's web-related learning environments (Janzen, 2014).

Keeler, (2014) mentioned several other advantages of using Google Classroom. She discusses how Google Classroom just makes it possible to streamline advice by posting an announcement. Ann D. Thompson, (2015) notes that interactive learning is enabled by Google Classroom. Teachers can submit materials here and can provide students with input. Students can also upload materials and make personal comments. Also, students can collaborate. They will share their records and tasks and thereby share them.

In the S1 Nutrition department, the application of Google Classroom is still rarely used and still few lecturers of the Nahdlatul Ulama University of Surabaya use this application maximally for teaching any courses, including in teaching English. Even, in this second semester, the students try this application for the first time in the English class for the nutrition profession. However, in the English class of this department (in the three classes), the English lecturer always used this application in teaching English. Although many lecturers in Universitas Nahdlatul Ulama Surabaya realize that Google Classroom has many benefits, only a few lecturers in this university have applied it maximally. In another aspect, the students look as if they master in using it. However, the research about the students' responses to using Google Classroom in the English class of nutrition profession has never been conducted. Therefore, this research focuses on students' responses to using Google Classroom in the English Class of the nutrition profession.

\section{B. METHOD}

The research is aimed to explore the students' responses of using Google Classroom in English Class of Nutrition Profession. This research uses a questionnaire survey to collect the data from the participants. The participants are 37 students of bachelor degree of nutrition profession of Nahdlatul Ulama University of Surabaya from three classes that are chosen through random sampling. This collected data from the survey data is collected through questionnaire survey from the students' responses. The collected data will be applied to gather the information needed. The survey which is in a form of questionnaire is distributed through social media (WhatsApp). The questionnaire contains of some questions. By conducting the survey through questionnaire, it can be explored students' responses of using Google Classroom in English Class of nutrition profession. Google Classroom application has been applied in all English classes of nutrition department so that the participants have already had some experiences in using it. Besides, the advantages and the disadvantages of using it in learning English can be found out through the students' responses. The data collected from the questionnaire survey is analyzed qualitatively.

The participants of this research are 60 students of bachelor degree of Nutrition Department of Nahdlatul Ulama University of Surabaya. They are in the second semester now. They are taking English course in this semester. There are three classess of this department. For this research, researcher only takes 37 students for each class through random sampling. During teaching and learning process, they apply Google Classroom totally, even in having an English test.

199 | IJET| Volume. 9, Issue 2. December 2020

Copyright 2020 Tiyas Saputri, Mujad Didien Afandi, and Badril Alamsyah are licensed under Creative Commons Atrribution- ShareAlike 4.0 International License. 
The procedures of this research are first, designing a questionnaire. It has 10 questions about using Google Classroom. Second, distributing it to the second semester of S1 nutrition students by the coordinator of English and with the help of the head of the S1 Nutrition department through WhatsApp group. Third, collecting the data obtained from it in a google spreadsheet. Fourth, analyzing the data through tabulation and empirical data in the percentage. Fifth, analyzing the data descriptively. Sixth, making results and discussion. The last, making a summary and conclusion.

\section{RESULT AND DISCUSSION}

The results of using Google Classroom (GC) in the English class of the nutrition profession are shown in some tables and figures. To find out the students' responses to using Google Classroom in the English class of nutrition professions, the students were surveyed for the research and given multiple options. Firstly, they were asked whether GC can accommodate e-learning. The findings were presented below:

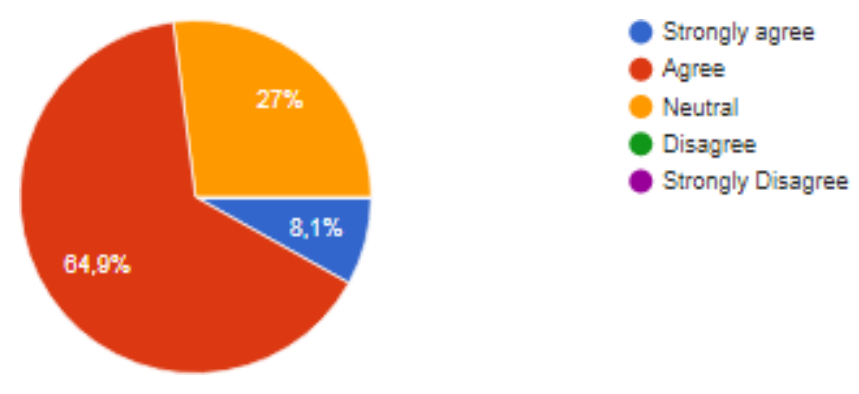

Figure 2. Students' responses that GC can accommodate e-learning

Based on the diagram above there was $64,9 \%$ of the students' responses agree that GC can accommodate e-learning, whereas there was $27 \%$ neutral and $8,1 \%$ strongly agree with the statement. While the rest $0 \%$ for disagree and strongly disagree.

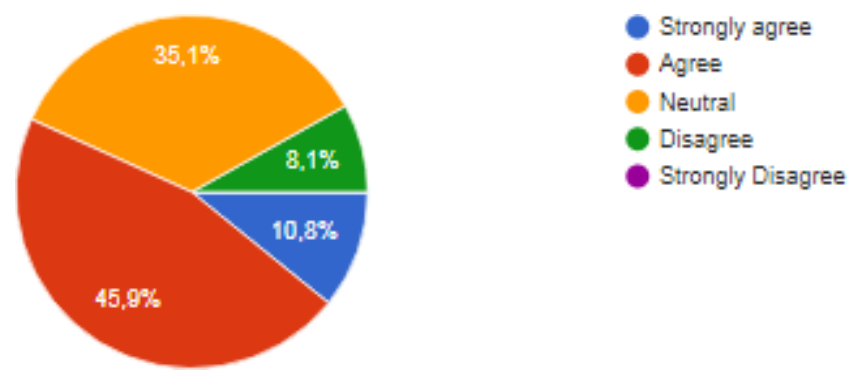

Figure 3. Students' responses that GC is as a character-building 
Based on the diagram above there was $45,9 \%$ of the students' responses agree that GC is character-building, whereas there was $35,1 \%$ neutral, $10,8 \%$ strongly agree and $8,1 \%$ disagree with the statement. While the rest $0 \%$ strongly disagree.

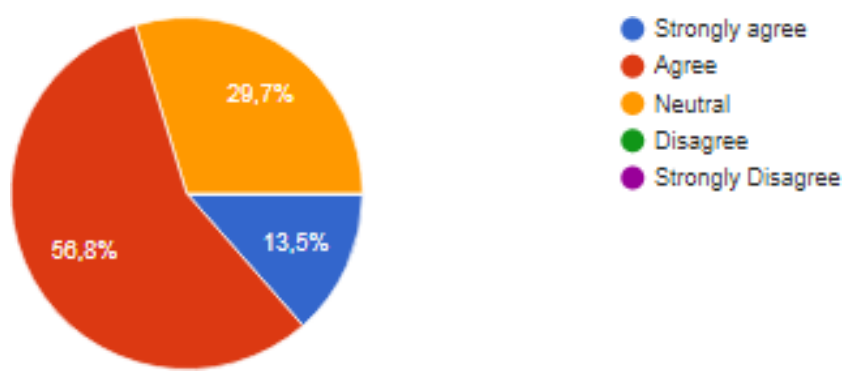

Figure 4. Students' responses that GC is a technological literacy exposure

Figure 4 presented that there was $56,8 \%$ of the students' responses agree that $\mathrm{GC}$ is a technological literacy exposure, whereas there was $29,7 \%$ neutral and $13,5 \%$ strongly agree with the statement. While the rest $0 \%$ for disagree and strongly disagree.

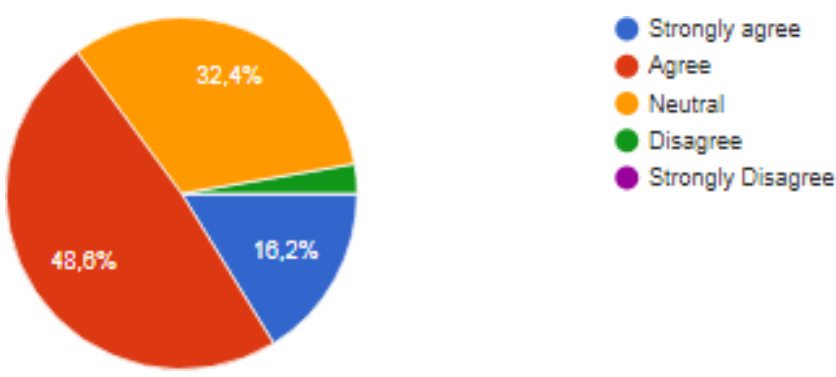

Figure 5. Students' responses that GC creates a paperless environment

Figure 5 presented that there was $48,6 \%$ of the students' responses agree that GC creates a paperless environment, whereas there was $32,4 \%$ neutral and $16,2 \%$ strongly agree with the statement. While the rest $2,7 \%$ disagree and $0 \%$ strongly disagree.

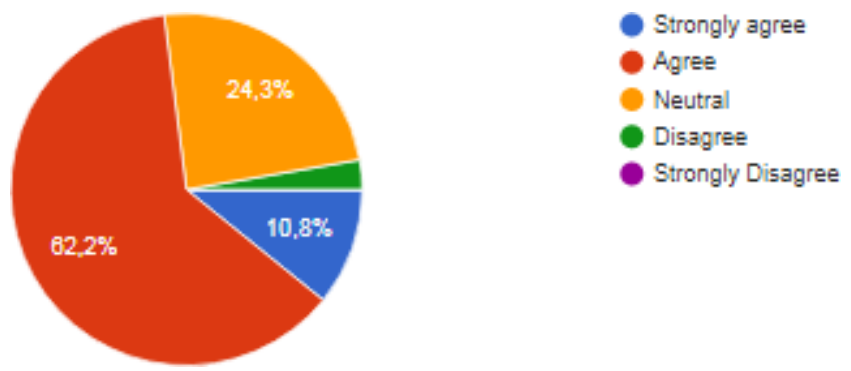

Figure 6. Students' responses that GC is as a material storage. 
Figure 6 presented that there was $62,2 \%$ of the students' responses agree that GC is as material storage, whereas there was $24,3 \%$ neutral and $10,8 \%$ strongly agree with the statement. While the rest $2,7 \%$ disagree and $0 \%$ strongly disagree.

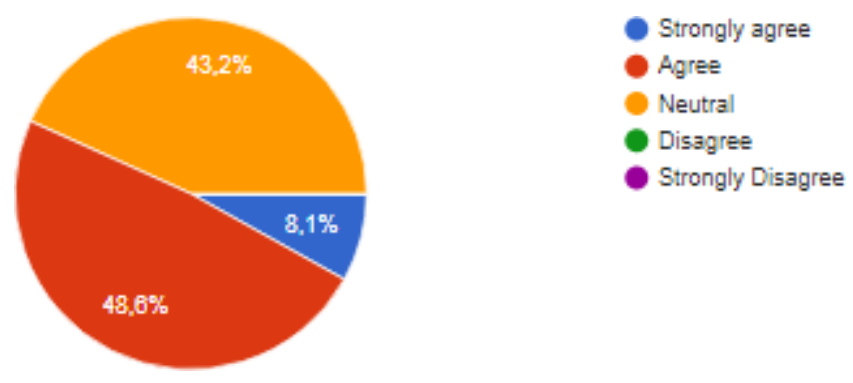

Figure 7. Students' responses that GC is an autonomous learning

Figure 7 presented that there was $48,6 \%$ of the students' responses agree that GC is autonomous learning, whereas there was $43,2 \%$ neutral and $8,1 \%$ strongly agree with the statement. While the rest $0 \%$ disagree and strongly disagree.
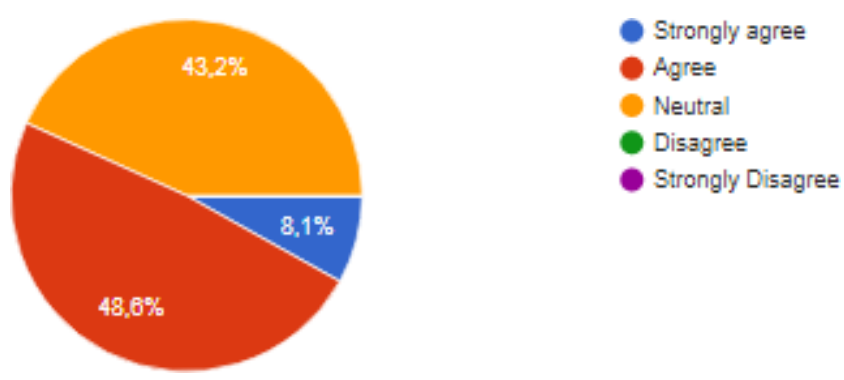

Figure 8. Students' responses that GC is as assessment transparency

Figure 8 presented that there was $48,6 \%$ of the students' responses agree that GC is as assessment transparency, whereas there was $43,2 \%$ neutral and $8,1 \%$ strongly agree with the statement. While the rest $0 \%$ disagree and strongly disagree.

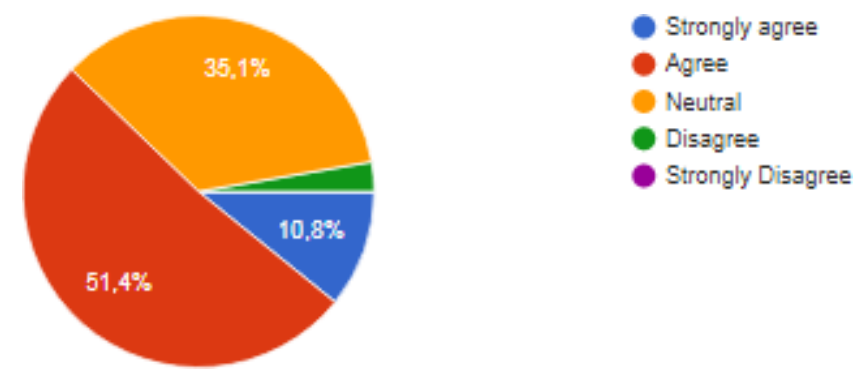


Figure 9. Students' responses that GC is as a task submission

Figure 9 presented that there was $51,4 \%$ of the students' responses agree that GC is a task submission, whereas there was $35,1 \%$ neutral and $10,8 \%$ strongly agree with the statement. While the rest $0 \%$ disagree and strongly disagree.

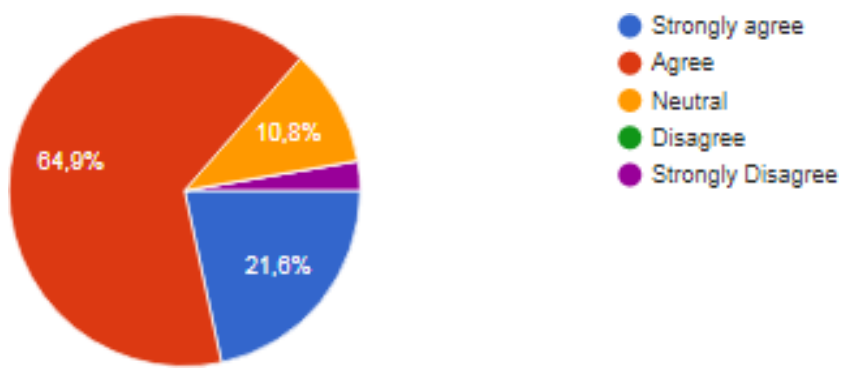

Figure 10. Students' responses that GC is easy to use

Figure 10 presented that there was $64,9 \%$ of the students' responses agree that GC is easy to use, whereas there was $10,8 \%$ neutral and $21,6 \%$ strongly agree with the statement. While the rest $2,7 \%$ strongly disagree and $0 \%$ disagree.
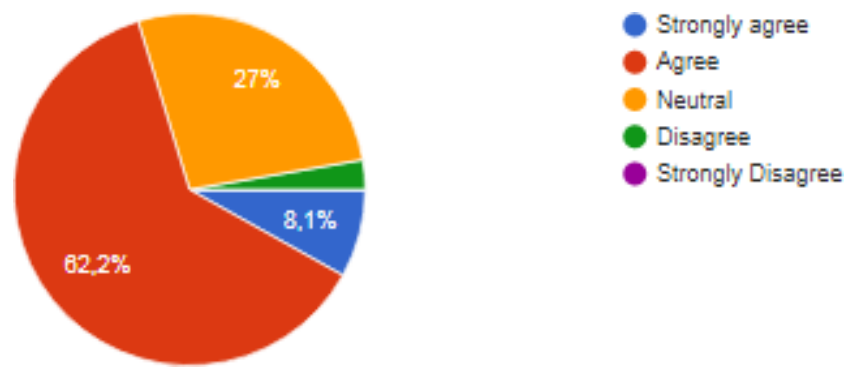

Figure 11. Students' responses that GC is effective to use

Figure 11 presented that there was $62,2 \%$ of the students' responses agree that GC is effective to use, whereas there was $27 \%$ neutral and $8,1 \%$ strongly agree with the statement. While the rest $2,7 \%$ disagree and $0 \%$ strongly disagree.

Table 1. The students' Responses of Using Google Classroom (GC) in English Class of Nutrition Profession

\begin{tabular}{|l|l|l|l|l|l|l|}
\hline \multirow{2}{*}{ No. } & \multirow{2}{*}{ Statement } & \multicolumn{3}{|l|}{ Average $(\%)$} \\
\cline { 3 - 7 } & & $\begin{array}{l}\text { Strongl } \\
\text { y Agree }\end{array}$ & Agree & Neutral & Disagree & $\begin{array}{l}\text { Strongly } \\
\text { Disagree }\end{array}$ \\
\hline 1 & GC can accommodate e-learning. & 8,1 & 64,9 & 27 & 0 & 0 \\
\hline
\end{tabular}




\begin{tabular}{|l|l|l|l|l|l|l|}
2 & GC is as a character building. & 10,8 & 45,9 & 35,1 & 8,1 & 0 \\
\hline 3 & $\begin{array}{l}\text { GC is a technological literacy } \\
\text { exposure. }\end{array}$ & 13,5 & 56,8 & 29,7 & 0 & 0 \\
\hline 4 & $\begin{array}{l}\text { GC creates a paperless } \\
\text { environment. }\end{array}$ & 16,2 & 48,6 & 32,4 & 2,7 & 0 \\
\hline 5 & GC is as material storage. & 10,8 & 62,2 & 24,3 & 2,7 & 0 \\
\hline 6 & GC is autonomous learning. & 8,1 & 48,6 & 43,2 & 0 & 0 \\
\hline 7 & GC is an assessment transparency. & 8,1 & 48,6 & 43,2 & 0 & 0 \\
\hline 8 & GC is a task submission. & 10,8 & 51,4 & 35,1 & 2,7 & 0 \\
\hline 9 & GC is easy to use. & 21,6 & 64,9 & 10,8 & 0 & 2,7 \\
\hline 10 & GC is effective to use. & 8,1 & 62,2 & 27 & 2,7 & 0 \\
\hline
\end{tabular}

Table 1 presented the students' responses to using Google Classroom (GC) in the English class of the nutrition profession. However, the researchers only highlighted 'Agree' as the highest percentage reached of each statement from the LIKERT scale (Strongly AgreeStrongly Disagree). From statement 1-10, only statement 1 (GC can accommodate e-learning) and statement 9 (GC is easy to use) which have reached 64,9\% (Agree). While the lowest percentage was $45,9 \%$ ( $\mathrm{GC}$ is as a character-building). It means that based on the students' responses to using GC in the English class of the nutrition profession, they agreed that GC has many benefits and the priorities of benefit are: it can accommodate e-learning and easy to use. Next, they also agreed that GC is effective to use and as material storage $(62,2 \%)$, it is a technological literacy exposure $(56,8 \%)$, it is as a task submission $(51,4 \%)$, it is autonomous learning, as assessment transparency and creates a paperless environment $(48,6 \%)$, it is as a character-building $(45,9 \%)$. However, statement 2 (GC is as a character-building) still needs to be explored further of the direct impact on the students for building their character. Therefore, this statement has the lowest percentage of 'Agree' based on the students' responses. For this point, it can be conducted further research about it.

Based on the result above, GC has many benefits and it can be the application which can be applied in teaching English for the nutrition profession in the S1 nutrition department. However, the lecturers and the students should keep applying GC as the application used in the English teaching and learning process of the nutrition profession so that they can operate it maximally and obtain the benefits of it. Furthermore, similar research can be conducted further in different fields or from the aspect of lecturers or both (lecturers and students) to recognize the benefits of using GC.

\section{CONCLUSION}

Google Classroom is one of the best platforms which can be used in the English teaching and learning process of the nutrition profession. Based on the students' responses of using Google Classroom (GC) in English class of nutrition profession, they agreed that GC has many benefits: it can accommodate e-learning, easy to use, effective to use, as material storage, a technological literacy exposure, as a task submission, autonomous learning, as assessment 
transparency and creates a paperless environment and as a character building. The results presented that from statements 1-10, only statement 1 (GC can accommodate e-learning) and statement 9 (GC is easy to use) which have reached 64,9\% (Agree). The lowest percentage was $45,9 \%$ (GC is as a character-building). They agreed that GC has many benefits and the priorities of benefit to accommodate e-learning and easy to use. However, the statement 'GC is as a character-building' still needs to be explored further of the direct impact on the students for building their character. Therefore, this statement has the lowest percentage of 'Agree' based on the students' responses. The lecturers and the students should keep applying GC as the application used in the English teaching and learning process of the nutrition profession so that they can operate it maximally and obtain the benefits of it. Furthermore, similar research can be conducted further in different fields or from the aspect of lecturers or both (lecturers and students) to recognize the benefits of using GC. Google Classroom is one of the best platforms which can be used in the English teaching and learning process of the nutrition profession. Based on the students' responses of using Google Classroom (GC) in English class of nutrition profession, they agreed that GC has many benefits: it can accommodate e-learning, easy to use, effective to use, as material storage, a technological literacy exposure, as a task submission, autonomous learning, as assessment transparency and creates a paperless environment and as a character building. The results presented that from statements 1-10, only statement 1 (GC can accommodate e-learning) and statement 9 (GC is easy to use) which have reached 64,9\% (Agree). The lowest percentage was $45,9 \%$ (GC is as a character-building). They agreed that GC has many benefits and the priorities of benefit to accommodate e-learning and easy to use. However, the statement ' $\mathrm{GC}$ is as a character-building' still needs to be explored further of the direct impact on the students for building their character. Therefore, this statement has the lowest percentage of 'Agree' based on the students' responses. The lecturers and the students should keep applying GC as the application used in the English teaching and learning process of the nutrition profession so that they can operate it maximally and obtain the benefits of it. Furthermore, similar research can be conducted further in different fields or from the aspect of lecturers or both (lecturers and students) to recognize the benefits of using GC.

\section{E. REFERENCES}

Al-maroof, R. A. S., \& Al-emran, M. (2018). Students Acceptance of Google Classroom : An Exploratory Study using PLS-SEM Approach. International Journal of Emerging Technologies in Learning (IJET), 13(06), 112-123. https://doi.org/https://doi.org/10.3991/ijet.v13i06.8275

Ann D. Thompson, D. L. \&Denise S.-C. (2015). NTLS 2014: Policy and Practice. Journal of Digital Learning in Teacher Education, 31(2). https://doi.org/https://doi.org/10.1080/21532974.2015.1019779

Azhar, K. A., \& Iqbal, N. (2018). Effectiveness Of Google Classroom : Teachers’ Perceptions. Prizren Social Science Journal, 2(2), 52-66.

Chehayeb, A. (2015). New in Classroom: Saving Time While Grading. Googleforeducation.Blogspot.Com. googleforeducation.blogspot.com/2015/12/new-inClassroom-saving-tim 
Dicicco, K. M. (2016). The Effects of Google Classroom on Teaching Social Studies for Students With Learning Disabilities Let Us Know How Access to This Document Benefits You - Share Your Thoughts On Our Feedback Form . [Rowan University]. https://rdw.rowan.edu/etd/1583

Iftakhar, S. (2016). Google Classroom: What Works and How? Journal of Education and Social Sciences, 3(1), 12-18.

Jakkaew, P. (2017). The Use of UTAUT2 Model for Understanding Student Perceptions Using Google Classroom: A Case Study of Introduction to Information Technology Course. IEEE, 17.

Janzen, M. (2014). Hot Team: Google Classroom. The Pennsylvania State University. tlt.psu.edu/2014/12/04/hot-team-google- classroom

Keeler, A. (2014). 20 Things You Can Do With Google Classroom. Prism News. https://alicekeeler.com/2014/09/07/20-things-google-classroom/

Megawati, F., \& Astutik, Y. (2019). EFL Learning Media : Perspective on E-Learning through Google Classroom. European Union Digital Library. https://doi.org/http://dx.doi.org/10.4108/eai.7-12-2018.2281768

Rabbi, M. F., Zakaria, A. K. M., \& Tonmoy, M. M. (2017). Teaching Listening Skill through Google Classroom : A Study at Tertiary Level in Bangladesh. DUET Journal, 3(1), 103108. 